\title{
A clinical study of suicide in patients admitted in psychiatry unit in Assiut University
}

\author{
Wageeh A. N. Hassan, Mostafa M. Noaman, Hossam Khalifa*, Ahmed A. Abdelrahman and Sally M. Omar
}

\begin{abstract}
Background: This study was performed for clinical study of suicide including risk factors in psychiatric patients admitted in psychiatric unit of Assiut University Hospital (AUH).

Results: We found that frequency of suicidal attempts is more in MDD (major depressive disorder), bipolar disorders followed by schizophrenia. And frequency of suicidal attempts in patients with multiple previous attempts before this one was higher in patients with mood disorders (53.8\%) than psychotic and substanceinduced disorders $(32.3 \%, 13.8 \%$ respectively), with statistically significant difference in patients with MDD as well as there was significant treatment outcome on suicidal behavior.
\end{abstract}

Conclusion: The frequency of suicidal attempts is more in MDD (major depressive disorder), bipolar disorders followed by schizophrenia. There was significant severity of suicidal behavior in patients with psychotic disorders in comparison to patients with substance-induced disorder or mood disorders.

Keyword: Suicide, Suicide attempts, Major depressive disorder, Bipolar disorder schizophrenia, Substanceinduced disorders

\section{Background}

Suicide (Latin suicide, from Sui caedere, "to kill oneself") is the act of intentionally causing one's own death. Suicide is often carried out as a result of despair, the cause of which is frequently attributed to a mental disorder such as depression, bipolar disorder, schizophrenia, borderline personality disorder, alcoholism, or drug abuse [1].

Factors that affect the risk of suicide include psychiatric disorders, drug misuse, psychological states, cultural, family and social situations, and genetics. Mental illness and substance misuse frequently co-exist. Other risk factors include having previously attempted suicide, the ready availability of a means to commit the act, a family history of suicide, or the presence of traumatic brain injury. For example, suicide rates have been found

* Correspondence: hossamkhalifa71@Yahoo.com

Psychiatry Unit, Department of Neurology and Psychiatry, Assiut University, Asyut, Egypt

\section{Springer Open}

to be greater in households with firearms than those without them [2].

Stress factors such as financial difficulties or troubles with interpersonal relationships often play a role. Efforts to prevent suicide include limiting access to firearms, treating mental illness and drug misuse, and improving economic circumstances [3].

Socio-economic problems such as unemployment, poverty, homelessness, and discrimination may trigger suicidal thoughts. About $15-40 \%$ of people leave a suicide note. Genetics appears to account for between 38 and $55 \%$ of suicidal behaviors. War veterans have a higher risk of suicide due in part to higher rates of mental illness [4].

Suicide prevention is a term used for the collective efforts to reduce the incidence of suicide through preventive measures. Reducing access to certain methods, such as firearms or toxins, reduces the risk. 
Treatment of drug and alcohol addiction, depression, and those who have attempted suicide in the past may also be effective. Some have proposed reducing access to alcohol as a preventive strategy (such as reducing the number of bars) [5].

In young adults who have recently thought about suicide, cognitive behavioral therapy appears to improve outcomes. Economic development through its ability to reduce poverty may be able to decrease suicide rates. Efforts to increase social connection especially in elderly males may be effective, the World Suicide Prevention Day is observed annually on September 10 with the support of the International Association for Suicide Prevention and the World Health Organization [6].

In those with mental health problems, a number of treatments may reduce the risk of suicide. Those who are actively suicidal may be admitted to psychiatric care either voluntarily or involuntarily. Possessions that may be used to harm oneself are typically removed. If a person is at low risk, out-patient mental health treatment may be arranged. Short-term hospitalization has not been found to be more effective than community care for improving outcomes in those with borderline personality disorder who are chronically suicidal [7].

There is tentative evidence that psychotherapy, specifically, dialectical behavior therapy reduces suicidality in adolescents, as well as in those with borderline personality disorder. It may also be useful in decreasing suicide attempts in adults at high risk. Evidence however has not found a decrease in completed suicides [8].

There is controversy around the benefit versus harm of antidepressants. In young persons, the newer antidepressants such as SSRIs appear to increase the risk of suicidality from 25 per 1000 to 40 per 1000 . Lithium appears effective at lowering the risk in those with bipolar disorder and unipolar depression to nearly the same levels as the general population. Clozapine may decrease the thoughts of suicide in some people with schizophrenia [9].

Suicide rates differ significantly between countries and over time. As a percentage of deaths in 2008, it was Africa $0.5 \%$, South-East Asia 1.9\%, America 1.2\%, and Europe 1.4\%.Rates per 100,000 were Australia 8.6, Canada 11.1, China 12.7, India 23.2, United Kingdom 7.6, USA 11.4, and South Korea 28.9. It is ranked as the 10th leading cause of death in the USA in 2009 at about 36,000 cases a year with about 650,000 people seen in emergency departments yearly due to attempting suicide. The country's rate among men in their 50's rose by nearly half in the decade 19992010. Lithuania, Japan, and Hungary have the highest rates. The countries with the greatest absolute numbers of suicides are China and India accounting for over half the total. In China suicide is the 5th leading cause of death [10].

\section{Methods}

Patients

One hundred patients (54 males and 46 females) participated in the study; they were admitted in the psychiatry unit of neurology and psychiatry department of Assiut University Hospital (AUH).

Selection criteria of the patients are as follows:

\section{Inclusion criteria}

1) Patients who fulfilled the criteria for the diagnosis of psychiatric disorders according to DSM-5 criteria [11].

2) Both sexes are included in the study.

\section{Exclusion criteria}

1) History of major neurological deficits or trauma.

2) Patients with chronic or serious medical condition that may affect cognition.

3) Patients who are their relatives refused to give informed consent.

\section{Study design}

It is a descriptive prospective study. The protocol and study design of this thesis were to be approved by the local ethical committee in the faculty of medicine, Assiut University. An informed consent was obtained from all the patients' first degree relatives.

\section{Duration}

The study took place from 1 March 2015 till 31 December 2015 .

\section{Methods}

All patients were interviewed guided by a psychiatric interview sheet of neurology and psychiatry department in Assiut University Hospital. It includes a detailed personal, family, medical, prenatal, scholastic, and past records as well as a detailed history of present illness including onset (acute or gradual), course (episodic or continuous), duration, symptoms, and reasons for seeking psychiatric help and past medication. Also, all patients were subjected to Sheehan suicidality tracking scale (S-STS) [11]. Suicide risk assessment scale: scale for impact of suicidality management, assessment and planning of care (SIS-MAP) [12], and disability rating scale (DRS) 
[14], after written informed consent obtained from each first degree relatives for his or her patients, also Sheehan suicidality tracking scale (S-STS) was applied to patients at admission and on discharge.

\section{Statistical analysis}

Data entry and data analysis were done using SPSS version 22 (Statistical Package for Social Science). Data were presented as number, percentage, mean, and standard deviation. Chi-square test was used to compare between qualitative variables. Mann-Whitney test was used to compare quantitative variables between two groups and Kruskal-Wallis test to compare quantitative variables among more than two groups, Wilcoxon signed-rank test was done to compare between pre- and post-treatment in case of nonparametric data. Spearman correlation was done to measure the correlation between quantitative variables. $P$ value considered statistically significant, when $P<0.05$.

\section{Results}

Tables 1, 2, 3, 4, and 5

\section{Discussion}

The socio-demographic data of the studied group showed that there was no statistically significant relation between age and the risk of suicide in which the mean age of the patients in the study was $30.34 \pm 10.78$ years, which is close to that in a study in which the mean age was 36.3 years [15]. Seventy-one percent of the patients $<35$ years of age, with decreasing frequency with increasing age, with patients older than 35 years of age representing 29\% of the sample, which is in agreement with studies reporting suicide to be more among young individuals than the elderly [16].

There was a high percentage of suicide in the age group 15-44 years in studies carried out in Egypt [16]. Among Arabs, suicide was more in the age group 20-40 years [17].

There was no statistically significant difference between sex and the risk of attempted suicide in the study. The male-to-female ratio was $1.17: 1$, which is close to the results of studies that showed no major difference regarding gender $[17,18]$.

However, a higher predominance of suicide rates in males over suicide rates in females was found to be 3.2:1 in 1950, 3.6:1 in 1995, and expected to become 3.9:1 in 2020 [20].

Table 1 Demographic characteristics of the studied sample

\begin{tabular}{|c|c|c|c|c|c|c|c|}
\hline & \multicolumn{2}{|c|}{ Total $(n=100)$} & \multicolumn{2}{|c|}{ Male $(n=54)$} & \multicolumn{2}{|c|}{ Female $(n=46)$} & \multirow[t]{2}{*}{$P$ value } \\
\hline & No. & $\%$ & No. & $\%$ & No. & $\%$ & \\
\hline \multicolumn{8}{|l|}{ Age } \\
\hline$<25$ years & 33 & 33.0 & 15 & 27.8 & 18 & 39.1 & 0.603 N.S \\
\hline $25-<30$ years & 21 & 21.0 & 12 & 22.2 & 9 & 19.6 & \\
\hline $30-<35$ years & 17 & 17.0 & 11 & 20.4 & 6 & 13.0 & \\
\hline$\geq 35$ years & 29 & 29.0 & 16 & 29.6 & 13 & 28.3 & \\
\hline Mean \pm SD (range) & \multicolumn{2}{|c|}{$30.34 \pm 10.78(12.0-61.0)$} & \multicolumn{2}{|c|}{$31.15 \pm 10.25(19.0-61.0)$} & \multicolumn{2}{|c|}{$29.39 \pm 11.42(12.0-55.0)$} & 0.420 N.S \\
\hline \multicolumn{8}{|l|}{ Education } \\
\hline Illiterate & 15 & 15.0 & 4 & 7.4 & 11 & 23.9 & \multirow[t]{4}{*}{$0.000^{* *}$} \\
\hline Read and write & 31 & 31.0 & 9 & 16.7 & 22 & 47.8 & \\
\hline Primary education & 48 & 48.0 & 35 & 64.8 & 13 & 28.3 & \\
\hline High education & 6 & 6.0 & 6 & 11.1 & 0 & 0.0 & \\
\hline \multicolumn{8}{|l|}{ Occupation } \\
\hline Not working & 63 & 63.0 & 18 & 33.3 & 45 & 97.8 & \multirow[t]{3}{*}{$0.000^{* *}$} \\
\hline Manual worker & 27 & 27.0 & 27 & 50.0 & 0 & 0.0 & \\
\hline Office worker & 10 & 10.0 & 9 & 16.7 & 1 & 2.2 & \\
\hline \multicolumn{8}{|l|}{ Marital status } \\
\hline Single & 48 & 48.0 & 31 & 57.4 & 17 & 37.0 & \multirow[t]{5}{*}{0.063 N.S } \\
\hline Married & 44 & 44.0 & 21 & 38.9 & 23 & 50.0 & \\
\hline Divorced & 3 & 3.0 & 2 & 3.7 & 1 & 2.2 & \\
\hline Separated & 3 & 3.0 & 0 & 0.0 & 3 & 6.5 & \\
\hline Widow & 2 & 2.0 & 0 & 0.0 & 2 & 4.3 & \\
\hline
\end{tabular}


Table 2 Psychiatric diagnoses among the studied sample

\begin{tabular}{|c|c|c|c|c|c|c|c|}
\hline \multirow[t]{2}{*}{ Diagnosis } & \multicolumn{2}{|c|}{ Total $(n=100)$} & \multicolumn{2}{|c|}{ Male $(n=54)$} & \multicolumn{2}{|c|}{ Female $(n=46)$} & \multirow[t]{2}{*}{$P$ value } \\
\hline & No. & $\%$ & No. & $\%$ & No. & $\%$ & \\
\hline Mood disorders & 61 & 61.0 & 27 & 50.0 & 34 & 73.9 & $0.015^{*}$ \\
\hline MDD & 41 & 41.0 & 14 & 25.9 & 27 & 58.7 & $0.001^{* *}$ \\
\hline MD.BPI. depression & 16 & 16.0 & 12 & 22.2 & 4 & 8.7 & 0.066 N.S \\
\hline MD.BPI. mania & 4 & 4.0 & 1 & 1.9 & 3 & 6.5 & 0.499 N.S \\
\hline Psychotic disorders & 24 & 24.0 & 12 & 22.2 & 12 & 26.1 & $0.652 \mathrm{NS}$ \\
\hline Brief-psychotic disorder & 2 & 2.0 & 0 & 0.0 & 2 & 4.3 & 0.406 N.S \\
\hline Schizophreniform disorder & 1 & 1.0 & 0 & 0.0 & 1 & 2.2 & 0.936 N.S \\
\hline Schizophrenia disorder & 12 & 12.0 & 9 & 16.7 & 3 & 6.5 & 0.212 N.S \\
\hline Schizoaffective disorder & 9 & 9.0 & 3 & 5.6 & 6 & 13.0 & 0.340 N.S \\
\hline \multicolumn{8}{|l|}{ Substance-induced disorder } \\
\hline Tramadol induced depression & 15 & 15.0 & 15 & 27.8 & 0 & 0.0 & $0.000^{* *}$ \\
\hline
\end{tabular}

The differences in male-to-female ratios can often be attributed to the use of more lethal suicide attempt methods, greater aggressiveness, and higher intent to die among men [20]. In contrast, women outnumbered men in terms of suicide attempts at a ratio of 2.2:1 [21].

In our study, $6 \%$ of the patients of the study at risk for suicide had high education with the highest risk of $79 \%$ for primary education; the group of patients with high education group had the lowest suicide risk with significant statistical difference $P$ value $=0.000$. A similar figure was found by [22]. Where the primary education group constituted $51.7 \%$ of their suicide cases, students showed the highest suicide risk (40\%) [19].

Table 3 History of previous suicidal attempts and methods used among patients in the studied sample

\begin{tabular}{lll}
\hline & No. $(n=100)$ & $\%$ \\
\hline History of previous suicidal attempts & & \\
Previous suicidal attempts & 65 & $\mathbf{6 5 . 0}$ \\
No previous suicidal attempts & 35 & $\mathbf{3 5 . 0}$ \\
Methods of suicidal attempts & & \\
Cut wrist & 24 & $\mathbf{2 4 . 0}$ \\
Jump from height & 13 & $\mathbf{1 3 . 0}$ \\
Burning & 4 & $\mathbf{4 . 0}$ \\
Stabbing self & 5 & $\mathbf{5 . 0}$ \\
Jump in front of moving vehicle & 1 & $\mathbf{1 . 0}$ \\
Drug overdose & 18 & $\mathbf{1 8 . 0}$ \\
Poison intake & 10 & $\mathbf{1 0 . 0}$ \\
Drowning & 5 & $\mathbf{5 . 0}$ \\
Hanging & 20 & $\mathbf{2 0 . 0}$ \\
\hline
\end{tabular}

Suicide mortality was also found to be more in the lower education group [18]. A higher suicide risk was found among those with primary to secondary level education and among students [23].

The influence of the level of education on suicide risk may be attributed to three different pathways. First, because those with a low education level cannot seek better jobs and accumulate material wealth, they may have a greater risk of suicide mortality because of lower job security and poor monetary conditions [24].

Second, education might have an independent effect on suicide, irrespective of occupation, and income [25]. Third, selection and recruitment into education might have an impact. Those with mental disorders and chronic severe illness as a proximal cause of suicide at younger ages might have left school without any qualification and might be less likely to have the opportunity for further education [23].

Among the study sample, $63 \%$ were unemployed, whereas the other $37 \%$ were working; $10 \%$ were skilled

Table 4 Relationship between frequency of previous suicidal attempts and disability in the studied sample

\begin{tabular}{lll}
\hline $\begin{array}{l}\text { Frequency } \\
\text { attempt }\end{array}$ & $\begin{array}{l}\text { DRS } \\
\text { Mean } \pm \text { SD }\end{array}$ & $P$ value \\
\hline No attempts & $7.34 \pm 2.13$ & 0.430 N.S \\
Once & $8.45 \pm 2.07$ & \\
Twice or more & $9.00 \pm 1.91$ & \\
No attempts & $7.34 \pm 2.13$ & $\mathbf{0 . 0 0 6 * *}$ \\
Attempts & $8.55 \pm 2.04$ & \\
\hline
\end{tabular}

$D R S$ disability rating scale ${ }^{* *}$ Significant difference $(P<0.01)$ 
Table 5 Severity of suicidal behavior in different diagnoses in the studied sample

\begin{tabular}{|c|c|c|c|c|}
\hline & \multicolumn{3}{|l|}{ Diagnosis } & \multirow[t]{3}{*}{$P$ value } \\
\hline & Mood disorders & Psychotic disorders & Substance-induced disorder & \\
\hline & Mean \pm SD & Mean \pm SD & Mean \pm SD & \\
\hline Suicidal ideation & $7.33 \pm 1.01$ & $7.33 \pm 0.92$ & $7.47 \pm 0.83$ & 0.897 N.S \\
\hline Suicidal intent factor & $25.00 \pm 5.83$ & $29.21 \pm 2.96$ & $26.67 \pm 3.83$ & $0.002^{* *}$ \\
\hline Suicidal planning score & $10.79 \pm 3.43$ & $12.21 \pm 1.82$ & $11.33 \pm 2.53$ & 0.131 N.S \\
\hline Suicidal behavioral score & $6.30 \pm 5.49$ & $9.54 \pm 3.82$ & $6.53 \pm 5.59$ & 0.106 N.S \\
\hline Pre S-STS & $32.97 \pm 12.33$ & $40.79 \pm 6.73$ & $33.93 \pm 8.79$ & $0.009 * *$ \\
\hline Suicidal ideation post & $1.82 \pm 1.15$ & $2.29 \pm 1.08$ & $1.60 \pm 0.99$ & 0.107 N.S \\
\hline Suicidal intent factor post & $2.67 \pm 2.15$ & $3.71 \pm 1.78$ & $2.40 \pm 1.92$ & $0.027^{*}$ \\
\hline Suicidal planning score & $0.67 \pm 0.98$ & $0.79 \pm 0.72$ & $0.53 \pm 0.92$ & 0.310 N.S \\
\hline Suicidal behavior score & $0.00 \pm 0.00$ & $0.00 \pm 0.00$ & $0.00 \pm 0.00$ & -- \\
\hline Post S-STS & $2.67 \pm 2.10$ & $3.71 \pm 1.78$ & $2.20 \pm 1.78$ & $0.018^{*}$ \\
\hline DRS & $8.02 \pm 1.89$ & $9.46 \pm 1.91$ & $6.47 \pm 2.23$ & $0.000^{* *}$ \\
\hline SIS-MAP & $44.92 \pm 10.86$ & $50.96 \pm 7.30$ & $44.67 \pm 11.51$ & 0.066 N.S \\
\hline
\end{tabular}

Pre S-TS pre Sheehan suicidality tracking scale, Post S-STS post Sheehan suicidality tracking scale, DRS disability rating scale, SIS-MAP scale for impact of suicidality management, assessment, and planning of care, N.S No significant difference $(P>0.05)$

*Significant difference $(P<0.05)$

${ }^{* *}$ Significant difference $(P<0.01)$

workers, whereas the rest $27 \%$ were unskilled workers with significant statistical difference $P$ value $=0.000$. In other studies, it was found that unemployed suicide victims represented $53 \%$ of the study sample [26].

Manual workers and unemployed individuals are at the highest risk of suicide [18]. Being unemployed was associated with a twofold to threefold increased relative risk of death by suicide compared with being employed [27].

In the study sample, only $44 \%$ were married, whereas $56 \%$ of the patients were either single (48\%), divorced, separated, or widowed (8\%)with no significant difference $P$ value $=0.062$ This was not very different from a study in Bahrain, in which $58.6 \%$ of the patients were single and divorced [22].

As reported by [26], study where patients showed a higher tendency to be single (43\%). This difference can be explained by the stigma of being divorced in the Arab world so they would prefer emotional separation and still married over the divorce.

Regarding the diagnosis in the studied sample, 61\% had mood disorders, $41 \%$ of them had major depressive disorder (MDD), 16\% had mood disorder bipolar I depressive episode, and $4 \%$ had mood disorder bipolar I manic episode. On the other hand, $24 \%$ of the patients had psychotic disorders, $12 \%$ of them had schizophrenia, $2 \%$ brief psychotic disorder, $9 \%$ schizoaffective disorder, and only $1 \%$ had schizophreniform disorder. Also $15 \%$ of our patients had substance-induced disorders.

This was consistent with study of [12] in which mood disorders were $57 \%$, substance-induced disorders $8 \%$, and psychotic disorders $27.3 \%$. It was also consistent with other studies as in a study done by [22], who found that mood disorders were at higher risk for suicide than other psychiatric illnesses.

There were no cases diagnosed with mental disorders due to brain damage, anxiety disorders, or mental subnormality in this work as the studied sample were among inpatients in Assuit University Hospital in which there were no admitted cases with such diagnoses during the time frame of the study.

Patients having a psychiatric illness for more than 5 years have increased risk of suicidality [22].

In this study, we recruited 100 patients with 54 male patients and 46 female patients.

In patients with mood disorders, MDD (major depressive disorder) was highly significant among females (58.7\%) $P$ value $=0.001$, also we found that MD. BP I mania (mood disorder, bipolar I mania) was slightly higher in females than males (6.5\%, 1.9\% respectively).

In contrast, MD. BPI depression (mood disorder, bipolar I depression) was higher in males than females (22.2\%, 8.7\% respectively). This is close to ArsenaultLapierre who found that the risk of mood disorders, specifically, depressive disorders, is greater in female suicides, and whereas mood disorders represented $59.4 \%$ of the female diagnoses and $47.4 \%$ of the male diagnoses $(P=0.089)$ [28].

However, [29] reported that male gender is predominant in patients with bipolar disorder who attempt suicide. In patients with psychotic disorders, the results showed that schizoaffective disorder, brief psychotic disorder, and schizophrenia form and were slightly higher in females than males $(13 \%, 4.3 \%, 2.2 \%, 5.6 \%, 0.0 \%$ respectively). 
On the other hand, schizophrenia disorder was slightly higher among male patients than females $(16.7 \%$, 6.5\% respectively).

This was close to [30] who found that in patients with psychosis the following risk factors for attempted suicide in the general community were being females.

All patients with tramadol-induced disorders were males with highly significant difference $P$ value $=0.000$

However, [31] found that young male SUD (substanceused disorder) patients may have psychosocial features associated with suicidality in common with female.

In the study sample, almost $35 \%$ of the patients did not have a history of previous suicidal attempts, whereas $65 \%$ had attempted suicide; $11 \%$ of suicide attempters were repeaters.

This was close to [32] in which $24.7 \%$ of the patients did not have a history of previous suicidal attempts, whereas $75.3 \%$ had attempted suicide; $50 \%$ of suicide attempters were repeaters.

Comparison of the frequencies of suicidal attempts between the patients showed that $81.5 \%$ of patients tried to commit suicide once, whereas $18.5 \%$ committed suicide twice and more. These results were similar to the findings of other studies which reflected that previous suicide attempts had a higher risk of suicidality [33].

A suicide attempt is a risk factor for completed suicide; the risk in individuals followed up for 5-37 years was $7-13 \%$ [34], roughly corresponding to a $30-40$ times increased risk of death from suicide in those who had attempted suicide compared with the general population [35].

The present study shows that frequency of suicidal attempts in patients with multiple suicide attempts before this one was more in MDD (major depressive disorder), bipolar disorders followed by schizophrenia in which patients with MDD with multiple previous attempts before this one was $(30.8 \%)$, bipolar disorders $(23.1 \%)$, schizophrenia (16.9\%), while patients with no previous attempts before this one were higher in MDD (60\%), tramadol-induced depression (17.1\%), followed by bipolar disorders $(14.3 \%)$ with $P$ value $=0.005$.

This is to some extent consistent with [35] who postulated that the rates of suicide after a previous suicide attempt were particularly increased among men and women with schizophrenia or bipolar and unipolar disorder. Population attributable fractions, expressing the impact of coexistent psychiatric disorder on suicide in people who had previously attempted suicide, suggested a modest but significant impact for other depression in women, schizophrenia in men, and bipolar and unipolar disorder in both sexes.

This also is close to Virkkunen 1974 [36] who reported that the life-time frequency of suicide attempts was high (between 23\% and 42\%) for all categories of psychotic disorders, with the exception of schizophreniform disorder. Although the risk of suicide is highest during the first 10 years of schizophrenia [36].

In this study, it was found that violent suicidal methods constituted $67 \%$ of the suicidal methods used; cutting of wrists was the most commonly used violent method, used by almost $24 \%$ of the patients, a number similar to another study that found that $25 \%$ of the patients had attempted to cut their wrists [15]. Also, cutting of wrists was found to be the most common violent method [37], followed by hanging (20\%). This is not consistent with Guwaili [15], it was only 3\%. Only $4 \%$ of suicide attempts were made by burning, whereas another study in Egypt found that among violent methods 36\% of patients attempted suicide by burning [15].

Drug overdose was the most commonly used nonviolent method (18\%), followed by poison intake (10\%); self-poisoning by a drug overdose or poison ingestion represented $80 \%$ of the nonviolent suicide methods [15]. Overdose by tablet ingestion was the most commonly used method in nonviolent suicide attempts (80\%) [38].

A study in Lebanon found that about $95 \%$ of individuals who attempted suicide used self-poisoning [37]. Most individuals (77\% men, 90\% women) used selfpoisoning in their suicide attempts [39]. This can be attributed to easy accessibility and availability of poisons and over-the-counter drugs in Egypt.

Our study also found that patients used violent methods was slightly higher in MDD (44.8\%), bipolar disorders (16.4\%) followed by schizophrenia (14.9\%) while the nonviolent methods were slightly higher in MDD (33.3\%), bipolar disorders (27.3\%) followed by schizoaffective disorder (18.2\%).

Suicidal intent factor was higher in psychotic disorders $29.21 \pm 2.96$ which was a significant difference in comparison to mood disorders and substance-induced disorders $(P$ value $=0.002)$, the same was found in total score of pre Sheehan suicidality tracking scale (pre S-STS) which was $40.79 \pm 6.73$ in psychotic disorders with $(P$ value $=0.009)$. This showed its impact on treatment outcome evaluated by post Sheehan suicidality tracking scale (post S-STS) as the score for suicidal intent factor was $3.71 \pm 1.78$ in psychotic disorders with $(P$ value $=$ 0.027 ) in comparison to mood disorders and substanceinduced disorders, post Sheehan suicidality tracking scale (post S-STS) score was $3.71 \pm 1.78$ with $(P$ value $=$ 0.018 ), this means a marked improvement in treatment, but treatment outcome was better in mood and substance-induced disorders in comparison to psychotic disorders; this was consistent with $[13,21]$ who found a high risk for suicide in schizophrenia, schizotypal, and delusional disorders [40].

Disability was higher in psychotic disorders evaluated by disability rating scale (DRS) in which $(P$ value $=$ 
0.000) which can be explained by the severity of psychotic disorders [41].

\section{Conclusion}

The frequency of suicidal attempts is more in MDD (major depressive disorder), bipolar disorders followed by schizophrenia. There was significant severity of suicidal behavior in patients with psychotic disorders in comparison to patients with substance-induced disorder or mood disorders.

\section{Abbreviations \\ AUH: Assiut University Hospital; MDD: Major depressive disorder; DSM- 5: Diagnostic and Statistical Manual of Mental Disorders fifth edition; S- STS: Sheehan suicidality tracking scale; DRS: Disability rating scale}

\section{Acknowledgements}

Not applicable.

\section{The committee's reference number}

Not available

\section{Authors' contributions}

$\mathrm{WH}$ contributed in the conception, the design of the work, and interpretation of the data. MN contributed in the interpretation of data and the creation of new software used in the work. HK contributed in the design of the work and interpretation of the data. AA and SO contributed in the acquisition, analysis, and revising the manuscript. All authors have read and approved the manuscript.

\section{Funding}

The authors of this manuscript declare that no funding bodies were involved in sponsoring or funding this research, no grants were taken, and the research was conducted solely on the expense of the authors.

\section{Availability of data and materials}

The datasets that were generated during and/or analyzed during the current study are available from the corresponding author on reasonable request.

\section{Ethics approval and consent to participate}

Before starting data collection, approvals to conduct the study were obtained from the Ethical Review Committee of Assiut Faculty of Medicine and the administrative authority in Neurological and Psychiatric Hospital at Assiut University. Prior to the interview, written informed consent was obtained from the literate participants and was signed in the presence of a witness for illiterate ones. Privacy and secrecy of all data were assured by ensuring the anonymity of the questionnaire, interviewing the participants separately in a closed room, and keeping data files in a safe place.

\section{Consent for publication}

Not applicable

\section{Competing interests}

All authors declare no actual or potential conflict of interest whether financial, personal, or otherwise related to this manuscript.

\section{Received: 27 March 2020 Accepted: 15 April 2020}

Published online: 09 July 2020

\section{References}

1. Paris J (2002) Chronic suicidality among patients with borderline personality disorder. Psychiatr Serv 53:738-742

2. Miller M, Azrael D, Barber C (2012) Suicide mortality in the United States: the importance of attending to method in understanding population-level disparities in the burden of suicide. Ann Rev Public Health 33:393-408

3. Sakinofsky I (2007) The current evidence base for the clinical care of suicidal patients: strengths and weaknesses. Can J Psychiatry 52:7-20
4. Quin P, Agerbo E, Mortensen PB (2003) Suicide risk in relation to socioeconomic, demographic, psychiatric, and familial factors: a national register-based study of all suicides in Denmark, 1981-1997. Am J Psychiatry 160:765-772

5. Yip PS, Caine E, Yousuf S, Chang SS, Wu KC, Chen YY (2012) Means restriction for suicide prevention. Lancet 379:2393-2399

6. Fässberg MM, van Orden KA, Duberstein P, Erlangsen A, Lapierre S, Bodner E, Canetto SS, De Leo D, Szanto K, Waern M (2012) A systematic review of social factors and suicidal behavior in older adulthood. Int J Env Res Public Health 9:722-745

7. Chang B, Gitlin D, Patel R (2011) The depressed patient and suicidal patient in the emergency department: evidence-based management and treatment strategies. Emerg Med Pract 13:1-23

8. Värnik P (2012) Suicide in the world. Int J Env Res Public Health 9:760-771

9. Hawton K, Saunders KE, O'Connor RC (2012) Self-harm and suicide in adolescents. Lancet 379:2373-2382

10. Haney EM, O'Neil ME, Carson S, Low A, Peterson K, Denneson LM, Oleksiewicz C, Kansagara D (2012) Suicide risk factors and risk assessment tools: a systematic review. Department of Veterans Affairs (US), Washington (DC)

11. American Psychiatric Association (APA) (2013) Diagnositc and statistical manual of mental disorders, 5th edn. American Psychiatric Publishing Arlington

12. Sheehan DV, Coric V, Distinto M, Pitanti M (2013) Sheehan suicidality tracking scale (S-STS). Compr Psychiatry. 54:842-849

13. Srivastava A, Nelson C (2008) Scale for impact of suicidality--management, assessment and planning of care (SIS-MAP), Amresh Srivastava: University of Western Ontario.

14. Rappoaport, Hall KM, Hopkins K, Belleza T, Cope DN(1982) Disability rating scale for sever head trauma patients: come to community. Arch Phys Med Rehabil 63:118- 123 .

15. Guwaili TA (1999) Clinical profile of attempted suicide. Faculty of Medicine, Cairo University, Cairo

16. Nock MK, Borges G, Bromet EJ, Cha CB, Kessler RC, Lee S (2008) Suicide and suicidal behavior. Epidemiol Rev 30:133-154

17. Okasha A (2004) Focus on psychiatry in Egypt. Br J Psychiatry 185:266-272

18. Karam EG, Hajjar RV, Salamoun MM (2008) Suicidality in the Arab world part II: community studies. Arab J Psychiatry 19:1-24

19. Bertoltte JM, Fleischmann A (2002) Suicide and psychiatric diagnosis: a worldwide perspective. World Psychiatry 1:181-185

20. Nock MK, Kessler RC (2006) Prevalence of and risk factors for suicide attempts versus suicide gestures: analysis of the national comorbidity survey. J Abnorm Psychol 115:616-623

21. Law S, Liu P (2008) Suicide in China: unique demographic patterns and relationship to depressive disorder. Curr Psychiatry Rep 10:80-86 BMC Public Health.

22. Al Ansari A, Ali MK (2009) Psychiatric and socioenvironmental characteristics of Bahraini suicide cases. East Mediterr Health J 15:1235-1241

23. Lee WY, Khang YH, Noh M, Ryu Jl, Son M, Hong YP (2009) Trends in educational differentials in suicide mortality between 1993-2006 in Korea. Yonsei Med J 50:482-492

24. Stack S (2000) Suicide: a 15-year review of the sociological literature. Part I: cultural and economic factors. Suicide Life Threat Behav 30:145-162

25. Khang YH, Kim HR (2005) Relationship of education, occupation and income with mortality in a representative longitudinal study of South Korea. Eur J Epidemiol 20:217-220

26. Wong PW, Chan WS, Chen EY, Chan SS, Law YW, Yip PS (2008) Suicide among adults aged 30-49: a psychological autopsy study in Hong Kong. BMC Public Health 8:147

27. Blakely TA, Collings SC, Atkinson J (2003) Unemployment and suicide. Evidence for a causal association? J Epidemiol Community Health 57:594-600

28. Arsenault-Lapierre G, Kim C, Turecki G (2004) Psychiatric diagnoses in 3275 suicides: a meta-analysis. BioMed Central Psychiatry 4:37

29. Oquendo MA, Galfalvy H, Russo S, Ellis SP, Grunebaum MF, Burke A, Mann J (2004) Prospective study of clinical predictors of suicidal acts after a major depressive episode in patients with major depressive disorder or bipolar disorder. Am J Psychiatry 161:1433-1441

30. Moscicki EK (1997) Identification of suicide risk factors using epidemiologic studies. Psychiatric Clin N A 20:499-517

31. Matsumoto T, Matsushita S, Okudaira K (2012) Sex differences in risk factors for suicidality among Japanese substance use disorder patients. Psychiatr Clin Neurosci 66:390-396 
32. Chastang F, Rioux P, Dupant I, Baranger E, Kovess V, Zarifian E (1998) Risk factors associated with suicide attempt in young French people. Acta Psychiatr Scand 98:474-479

33. Vijayakumar L, John S, Pirkis J, Whiteford H (2005) Suicide in developing countries (2): risk factors. Crisis 26:112-119

34. Suominen K, Isometsä E, Ostamo A, Lönnqvist J (2004) Level of suicidal intent predicts overall mortality and suicide after attempted suicide: a 12year follow-up study. BMC Psychiatry 4:11

35. Tidemalm D, Långström N, Lichtenstein P, Runeson B (2008) Risk of suicide after suicide attempt according to coexisting psychiatric disorder: Swedish cohort study with long term follow-up. BMJ 337:2205

36. Virkkunen M (1974) Suicides in schizophrenia and paranoid psychoses. Acta Psychiatrica Scandinavica 250:305-310

37. Alyahfoufi N (1998) Attempted suicide in Lebanon. Arab Psychiatry J 9:109-116

38. Okasha A, Kamel M, Lotaif F, El-Mahalawy N, Khalil AH, Ashour AM (1986) Descriptive study of attempted suicide in Cairo. Egypt J Psychiatry 9:53-70

39. Runeson B, Tidemalm D, Dahlin M, Lichtenstein P, Langstrom N (2010) Method of attempted suicide as predictor of subsequent successful suicide: national long term cohort study. BMJ 341:3222

40. De Leo D, Klieve H (2007) Communication of suicide intent by schizophrenic subjects: data from the Queensland suicide register. Int J Mental Health 1:6-12

41. Penrose LS (1938) A clinical and genetic study of 1280 cases of mental defect. Medical Research Council: Special Report Number 229.

\section{Publisher's Note}

Springer Nature remains neutral with regard to jurisdictional claims in published maps and institutional affiliations.

\section{Submit your manuscript to a SpringerOpen ${ }^{\circ}$ journal and benefit from:}

- Convenient online submission

- Rigorous peer review

- Open access: articles freely available online

- High visibility within the field

- Retaining the copyright to your article

Submit your next manuscript at $\boldsymbol{\nabla}$ springeropen.com 